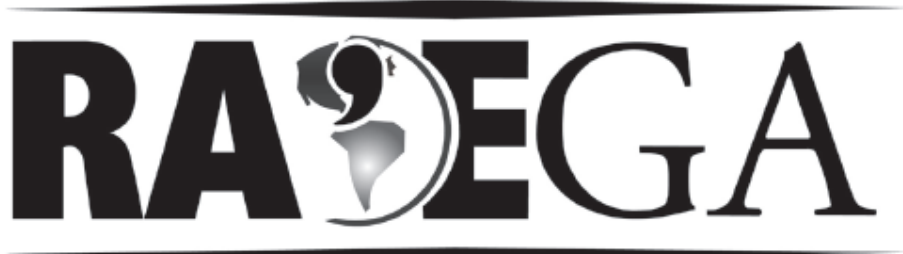

O ESPAÇO GEOGRÁFICO EM ANÁLISE

\title{
RELAÇÃO ENTRE TEMPERATURA DE SUPERFÍCIE TERRESTRE, ÍNDICES ESPECTRAIS E CLASSES DE COBERTURA DA TERRA NO MUNICÍPIO DE GOIÂNIA (GO)
}

\section{RELATION BETWEEN LAND SURFACE TEMPERATURE, SPECTRAL INDICES AND LAND COVER CLASSES IN THE CITY OF GOIÂNIA (GO)}

\author{
Silvio Braz de Sousa ${ }^{1}$ \\ Laerte Guimarães Ferreira Júnior²
}

\section{Resumo}

Partindo-se do conceito de heterogeneidade da paisagem urbana, espera-se que diferentes paisagens apresentem distintos comportamentos termais, visto que, cada espaço da cidade possui particularidades quanto aos tipos e intensidades de cobertura e uso da terra. O presente trabalho, tendo como área de estudo o município de Goiânia, capital do estado de Goiás, busca analisar a relação dos diversos tipos de uso e intensidade de urbanização com 0 comportamento térmico superficial e, sua correlação com índices espectrais (NDBI e SAVI), utilizando para isso dados do sensor ETM+ abordo do satélite Landsat 7. Foram efetuadas amostragens aleatórias e utilizado como referência para a definição de uso e cobertura da terra uma imagem de alta resolução do satélite Quickbird. NDBI e temperatura de superfície terrestre apresentaram boa correlação $\left(r^{2}\right.$ de 0,74$)$. Áreas com cobertura de solo exposto, como áreas de plantio, queimadas e bairros sem cobertura asfáltica registraram altas

\footnotetext{
${ }^{1}$ Mestrando do Programa de Pós Graduação em Geografia - UFG/IESA. Caixa Postal: 131 CEP 74001940 Campus Samambaia Goiânia (GO) - Brasil. Fone: (+ 55 62) 35211360 - sousasb@gmail.com

${ }^{2}$ Pós-Graduação em Geografia da Universidade Federal de Goiás. laerte@iesa.ufg.br
} 
temperaturas (maiores que $\left.38^{\circ} \mathrm{C}\right)$. As temperaturas amenas registradas $(<23$ e $\left.30^{\circ} \mathrm{C}\right)$ correspondem a áreas de vegetação densa, como as matas de galerias, o Jardim Botânico e o Parque Estadual Altamiro de Moura Pacheco, registrou-se uma diferença de até $8^{\circ} \mathrm{C}$ em relação a áreas antropizadas.

Palavras-chave: Temperatura de Superfície Terrestre; Sensoriamento Remoto; Sensor ETM+; Áreas Urbanas.

\begin{abstract}
Starting from the concept of urban landscape heterogeneity, it is expected that different landscapes have different thermal behaviors, since each city space has particularities regarding the types and intensities of land use and cover. This study, having as the study area the city of Goiânia, capital of the state of Goias, seeks to analyze the relationship of the various types of use and intensity of urbanization with the superficial thermal behavior, and its correlation with spectral indices (SAVI and NDBI) using for that data from the ETM + sensor aboard the Landsat 7 satellite. Random samplings were performed and it was used a high resolution image of the Quickbird satellite as reference. NDBI and land surface temperature showed good correlation $\left(r^{2}=0.74\right)$. Areas with land cover of exposed soil, such as planting areas, burned areas and neighborhoods without asphalt coverage recorded high temperatures (greater than $38^{\circ} \mathrm{C}$ ). The warm temperatures recorded ( $<23$ and $\left.30^{\circ} \mathrm{C}\right)$ corresponded to areas of dense vegetation, such as gallery forests, the Botanical Garden and the State Park Altamiro de Moura Pacheco, recording a difference of up to $8{ }^{\circ} \mathrm{C}$ in relation to anthropic areas.
\end{abstract}

Key words: Land Surface Temperature; Remote Sensing; ETM+ sensor; Urban Areas.

\title{
INTRODUÇÃO
}

A temperatura de superfície terrestre (TST) é importante parâmetro nos estudos termais do ambiente urbano e suas dinâmicas (WENG, 2009). As trocas e o balanço de energia superficial são funções da interação da radiação com a cobertura da terra, as quais podem desdobrar apontamentos em relação ao clima urbano, ao nível de planejamento e a qualidade de vida da população.

Santos (1994) considera a cidade como um meio ambiente construído, retrato da diversidade das classes, das diferenças de renda e dos modelos culturais. Nesse sentido, pode-se pensar a paisagem urbana como um conjunto heterogêneo e, as mudanças no campo térmico urbano como resultado desse caráter segregador e fragmentador da população entre bairros de diferentes classes e rendas, que possuem suas particularidades quanto ao planejamento, 
arborização e o acesso a áreas de maior extensão que promovem menor intervenção no meio físico natural.

A ideia de uma paisagem urbana heterogênea pode ser reforçada pela reflexão acerca das considerações de George (1968) que considera o espaço um manteau d' Arlequin, "feito de justaposição de porções, mais ou menos grandes, apresentado cada uma, relativamente diversas necessidades ou diversas intenções de utilização, virtualidades diferentes". Pensamos o mesmo para o espaço urbano, principalmente em relação ao espaço de uma metrópole, como é o caso de Goiânia, marcada por uma pluralidade de agentes, por horizontalidades e verticalidades.

No espaço da metrópole os atributos humanos e ambientais são somados, formando paisagens heterogêneas, marcadas profundamente pela relação do ser humano com o meio e, principalmente dos homens entre os homens. As diversas territorialidades, os diversos atores, os diferentes níveis de acesso a terra e a técnica, fazem da metrópole o encontro da diversidade e por que não, um campo de lutas.

Partindo-se do conceito de heterogeneidade da paisagem urbana, espera-se que diferentes paisagens apresentem distintos comportamentos termais, visto que, cada espaço da cidade possui particularidades quanto aos tipos e intensidades de cobertura e uso da terra, o que reflete nas condições ambientais e na relação de balanço e troca de energia entre a superfície e a atmosfera. As informações sobre a temperatura superficial podem ser obtidas por sensoriamento remoto. Isto, porque o calor interno de um objeto é convertido em energia radiante e para a maioria dos objetos existe uma alta correlação positiva entre a temperatura cinética verdadeira do objeto e o fluxo radiante radiado pelo objeto (JENSEN, 2009, p.255). Este fluxo radiante emitido em comprimentos de onda longos $(3-14 \mu \mathrm{m})$ pode ser registrado usando detectores de infravermelho acoplados a plataformas orbitais como também aerotransportados.

O objetivo deste trabalho é analisar a relação entre diversos tipos de uso e intensidade de urbanização e o comportamento térmico, atentando-se para 
os diferentes padrões de urbanização existentes na capital goiana, e sua correlação com índices espectrais, utilizando para isso a técnica de sensoriamento remoto por meio de imagens do sensor ETM+ a bordo do satélite Landsat 7.

\section{Área de Estudo}

O município de Goiânia, capital do estado de Goiás, situado na região Centro-Oeste do Brasil (Figura 01) e inserido no bioma Cerrado, possui uma área aproximada de $733 \mathrm{~km}^{2}$, altitude média aproximada de $791 \mathrm{~m}$ e uma população estimada de 1.301 .892 habitantes (IBGE, 2011).

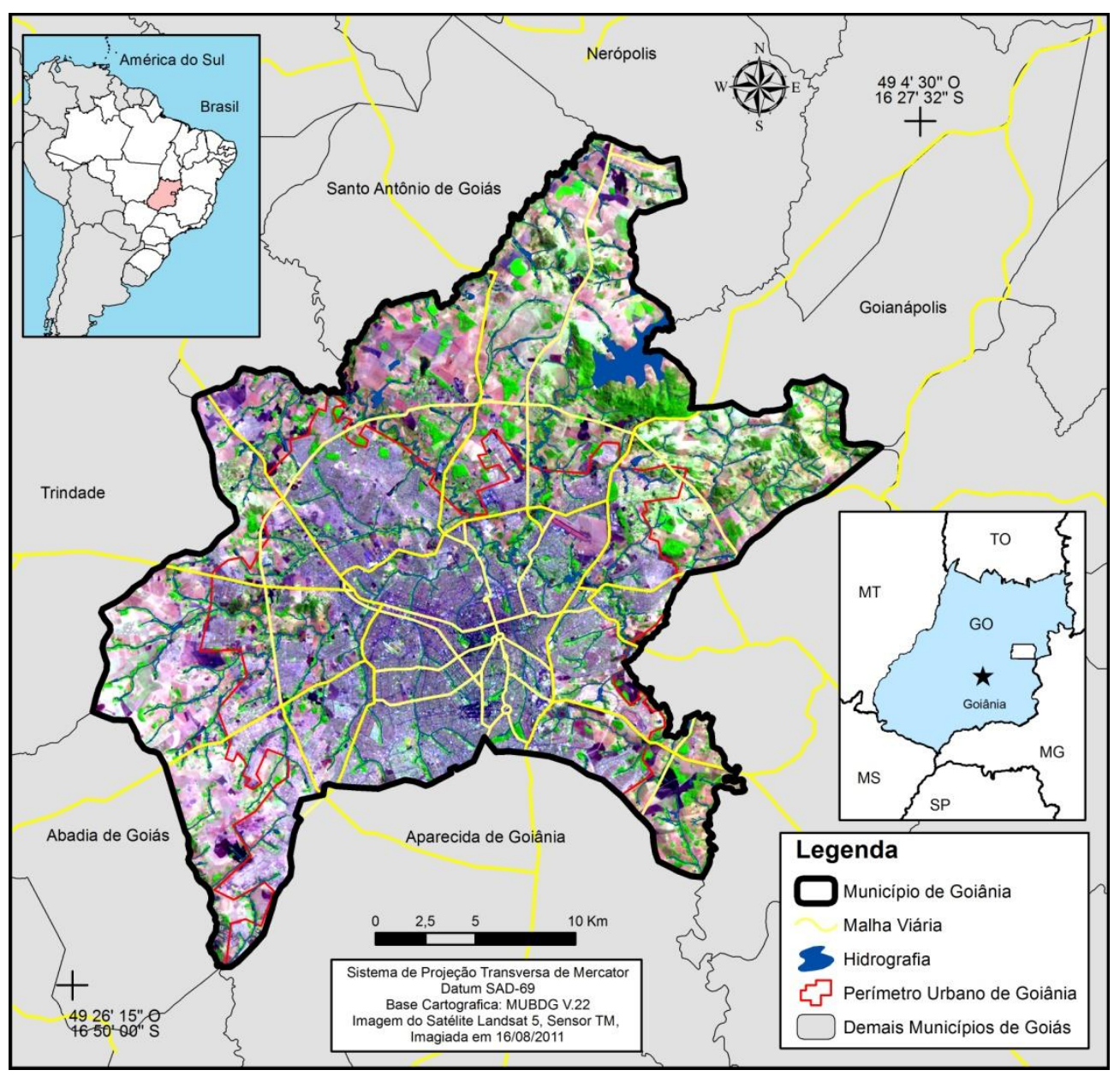

Figura 1 - Carta-imagem de localização de Goiânia, Goiás, 2011. 
Goiânia, inaugurada em 1934, é marcada por um intenso crescimento populacional desde 1950, quando a cidade se tornou destino de migrantes de todas as partes do país, intensificado-se na década de 60 com a construção de Brasília e da rodovia Belém-Brasília, que promoveram intensos fluxos demográficos e econômicos (NASCIMENTO, 1993 p. 95).

$\mathrm{Na}$ década de 1970, Goiânia passou por um novo impulso de crescimento populacional, adentrando a década de 1980 com 717.526 habitantes. Esse processo se deu por migrantes interestaduais, como também por populações dos municípios do interior de Goiás (CHAUL 1988, p.109), haja vista que, com a modernização da agricultura, a população rural veio buscar trabalho na capital. A tabela 1 mostra a evolução da população de Goiânia entre as décadas de 1940 a 2010.

Tabela 1 - População residente no município de Goiânia - 1940 a 2010. Fonte: IBGE, 2011.

\begin{tabular}{|c|c|c|c|c|c|c|c|c|}
\hline \multicolumn{9}{|c|}{ População residente no município de Goiânia - 1940 a 2010} \\
\hline \multirow{2}{*}{$\begin{array}{l}\text { Município de } \\
\text { Goiânia }\end{array}$} & \multicolumn{8}{|c|}{ População Residente } \\
\hline & 1940 & 1950 & 1960 & 1970 & 1980 & 1991 & 2000 & 2010 \\
\hline Urbana & & & 133.462 & 363.056 & 703.682 & & 1.085 .806 & \\
\hline Rural & & 13.056 & 17.717 & 17.717 & 13.844 & & 7.201 & \\
\hline Total & 48.166 & 53.389 & 151.013 & 380.773 & 717.526 & 922.222 & 1.093 .007 & 1.302 .001 \\
\hline
\end{tabular}

Um dos critérios na escolha da área de estudo deste trabalho foi justamente o crescimento demográfico de Goiânia, que provocou grande expansão da malha urbana, gerando bairros de diversos padrões de urbanização e planejamento, como: condomínios horizontais fechados de alto padrão, ocupações de áreas de risco, parcelamentos nas mais diversas dimensões, bairros com presença de sub-centros comerciais e de serviços, etc.

Outros dois critérios podem ser considerados na escolha da área de estudo: 1) A disponibilidade dos dados de referência, por meio de imagem do satélite Quickbird (2002) e do Mapa Urbano Básico Digital de Goiânia em sua versão 22 (MUBDG v22); 2) A topografia do município que se apresenta em 
grande parte plana à suave ondulada, já que Landsberg (2006) considera que muitos dos contrastes observados nas propriedades térmicas existentes nas cidades podem ser em função da topografia. Desta forma, espera-se que em Goiânia exista maior correlação espacial dos valores de temperatura superficial com o uso e cobertura da terra.

\section{MATERIAIS E MÉTODOS}

Todos os procedimentos metodológicos envolvidos neste estudo, os quais incluíram aquisição, processamento e calibração de imagens, amostragens e análises de dados, são detalhados no fluxograma mostrado na figura 2.

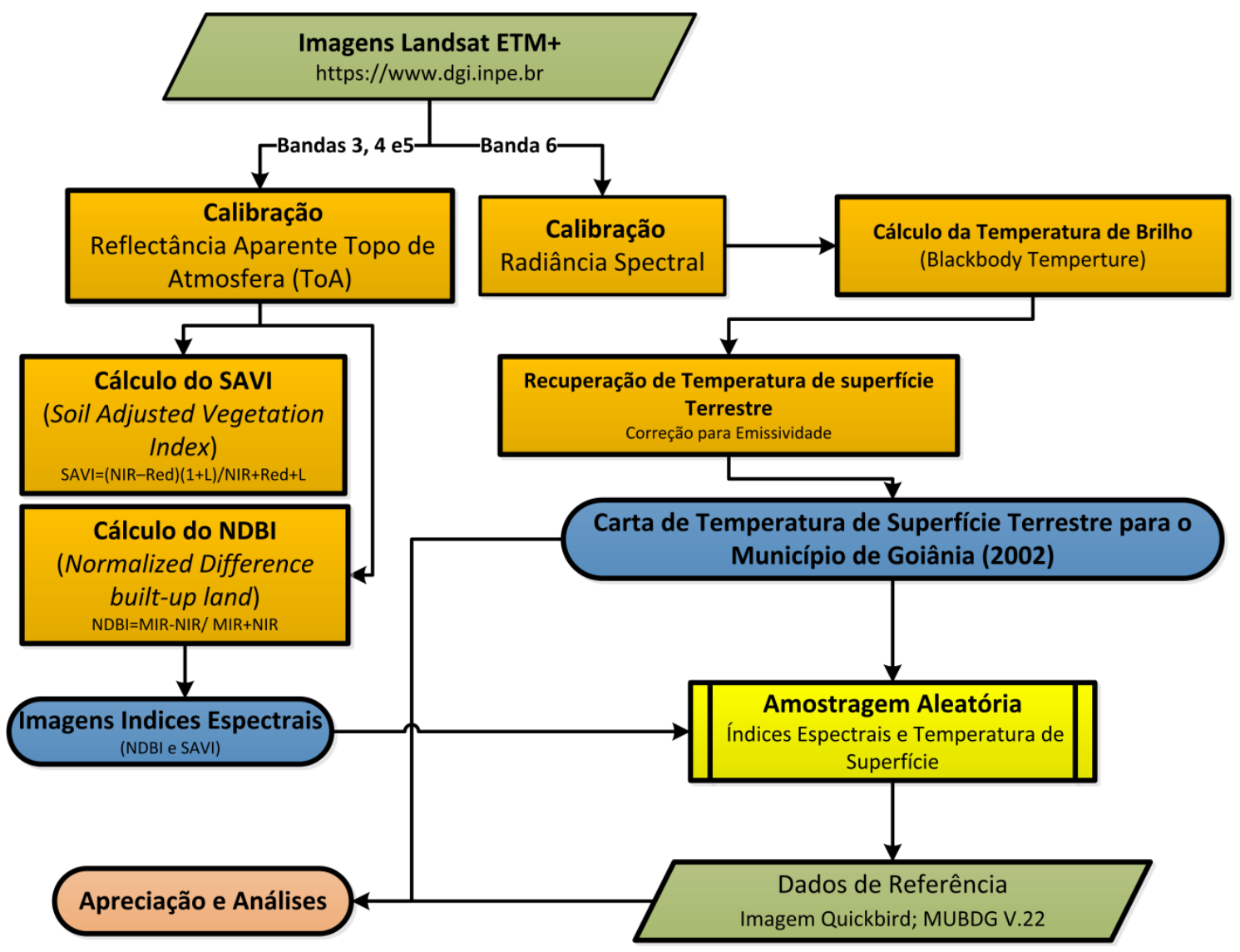

Figura 2: Fluxograma esquemático referente ao conjunto de dados e procedimentos metodológicos adotados neste estudo. 


\section{Dados Landsat}

Os dados Landsat utilizados para obtenção dos valores de temperatura de superfície terrestre são imagens do Satélite Landsat 7, Sensor ETM+, órbita/ponto 222/71 e 222/72, de 15 de agosto de 2002, as quais foram reprojetadas para o fuso UTM 22S, Datum WGS 1984, conforme 35 pontos de controle bem distribuídos, o que resultou em um erro médio quadrático de 0,35 pixel.

O ano de 2002 foi selecionando devido à disponibilidade de imagens do sensor $\mathrm{ETM}+$, o qual apresenta maior resolução espacial para a banda termal (60m), comparativamente ao sensor TM do Landsat 5 (120m). O ano de 2002 também coincide com o ano da imagem Quickbird disponível, utilizada como referência principal quanto aos padrões de cobertura e uso da terra para o município de Goiânia. Destaca-se a escolha do mês de agosto, cujo período de seca proporciona menor cobertura de nuvens, bem como pouco vapor de água na atmosfera, que trata-se de um dos maiores absorvedores da radiação emitida pela superfície na faixa do infravermelho termal.

\section{Dados de Referência}

Os dados de referência para análise do padrão espacial da temperatura de superfície terrestre, em relação à cobertura e uso da terra, foram adquiridos por meio de dados imageados em 2002 pelo satélite Quickbird, com resolução espacial de aproximadamente $0,62 \mathrm{~cm}$. Dados vetoriais do Mapa Urbano Básico Digital de Goiânia (MUBDG v.22), também foram utilizados.

\section{Calibração e Recuperação da Temperatura de Superfície Terrestre}

A recuperação de valores de temperatura superficial com base em imagens colhidas na região do infravermelho termal exige uma abordagem complexa, na qual são utilizados diversos algoritmos e uma série de dados 
intrínsecos e extrínsecos ao sensor remoto utilizado (parâmetros de calibração). Para este trabalho, os parâmetros de calibração foram adquiridos por meio do calibration parameter file (CPF) no EROS data Center (http://eros.usgs.gov/), como também no trabalho de Chander et. al. (2009).

A conversão dos valores de níveis de cinza da banda 6 TM e ETM+ em radiância espectral foi realizada através do método Spectral Radiance Scaling Method (eq. 2):

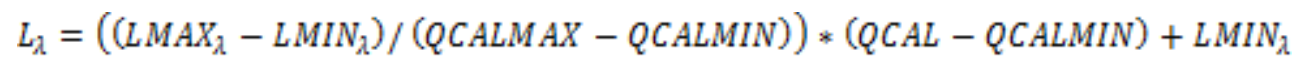

Onde:

$\mathrm{L}_{\lambda}=$ Radiância da banda termal

LMAX e LMIN = Parâmetros de radiância espectral para cada banda.

QCALMIN = Mínimo nível de cinza a ser calibrado (Landsat geralmente $=1$ )

QCALMAX = Máximo nível de cinza a ser calibrado (Landsat geralmente $=255$ )

QCAL = Nível de cinza de cada pixel (dados de entrada, bandas)

Todas as bandas do espectro refletido e a banda termal foram submetidas à equação 1. A partir daí, o tratamento das imagens tomou dois caminhos: 1) As bandas do espectro refletido ETM+ 5, 4 e 3 foram submetidas à equação 2 para obtenção da reflectância aparente topo de atmosfera (ToA); 2) A banda termal foi submetida a equação 3 para recuperação da temperatura de brilho. Posteriormente, a temperatura de brilho foi submetida à equação 4 que corrige a temperatura de brilho para uma emissividade constante e, assim, finalmente chegar aos valores estimados de temperatura de superfície terrestre.

Abaixo, a equação 2 utilizada para recuperar os valores de reflectância aparente topo de atmosfera:

$$
\rho_{\lambda=\frac{\pi \times L_{\lambda} \times d^{2}}{E S U N_{\lambda} \times \cos \theta_{S}}}
$$

Onde: 
$\rho n-$ Reflectância aparente topo de atmosfera (ToA)

L $\lambda$ - Radiância espectral [W/(m2 sr $\mu \mathrm{m})]$

d - Distância Terra Sol para o dia do ano em unidades astronômicas

ESUN $\lambda$ - Irradiâncias solares exo-atmosfera [W/(m2 m)]

$\theta \mathrm{s}-$ Ângulo zenital solar em graus

Por fim, apresentamos as equações 3 e 4, aplicada somente na banda termal $(E T M+6)$ já calibradas para radiância espectral, afim de recuperar a temperatura de brilho e correção para emissividade constante:

$$
T_{B}=\frac{K 2}{\ln \left(\frac{K 1}{L_{\lambda}}+1\right)}
$$

Onde:

$T_{B}=$ Temperatura de brilho

K1 - Constante de calibração para a banda termal 1

K2 - Constante de calibração para a banda termal 2

L - Radiância espectral

$$
S_{t}=\frac{T_{B}}{1+\left(\lambda \times T_{B} / \rho\right) \times \ln \varepsilon}
$$

Onde: $\lambda=$ é comprimento de onda médio da radiação emitida em micrometros, $\rho=h \times\left(\frac{c}{\sigma}\right)=1.438 \times 10^{-2}(\mathrm{mK}), \sigma$ é a constante de Boltzman $\left(1,38 \times 10^{-23}\right.$ $\mathrm{J} / \mathrm{K})$, h é a constante de Planck $\left(6.626 \times 10^{-34} \mathrm{Js}\right)$, c é a velocidade da luz $\left(2.998 \times 10^{8} \mathrm{~m} / \mathrm{s}\right)$, e $\varepsilon$ é emissividade no intervalo entre 0.0 e 1.0 .

O valor de emissividade adotado para as bandas termais (TM e ETM+) foi de 0,96 , o qual corresponde à emissividade média para todos os alvos passíveis de serem identificados na imagem. 


\section{Índices utilizados}

Foram utilizados dois índices espectrais nesse trabalho, os quais foram construídos por meio de aplicação de equações utilizando as imagens já calibradas para reflectância aparente topo de atmosfera (ToA). São eles: 0 NDBI (Normalized Difference Built-up Land Index) adaptado de Zha et. al. (2003) e um índice de vegetação, o SAVI (Soil Adjusted Vegetation Index). O NDBI foi calculado utilizando a seguinte equação:

$$
N D B I=\frac{M I R-N I R}{M I R+N I R}
$$

O NDBI tem como base o fato de que terras construídas têm maior reflectância no infravermelho de ondas médias do que no infravermelho de ondas curtas (XU HANQIU, 2007). Espera-se com este índice que ele apresente maiores valores em áreas mais densamente urbanizadas.

Para o cálculo do SAVI foi utilizada a seguinte equação:

$$
S A V I=\frac{(N I R-R E D)(1+L)}{N I R+R E D+L}
$$

$\mathrm{Na}$ qual $\mathrm{L}$ é um fator de correção que varia de 0 a 1 , sendo 0 representante de áreas com alta densidade de vegetação e 1 áreas de baixa densidade. Para o município de Goiânia utilizou-se o fator de correção de 0.5, já que este representa uma região moderadamente vegetada. Segundo $X U$ Hanqiu (2007) o SAVI, além de ser um índice de vegetação modificado para considerar a presença do solo, apresenta melhor desempenho em realçar a vegetação em áreas construídas com cobertura vegetal menor que 15\%, aumentando o contraste entre as áreas construídas e a vegetação natural. 


\section{Amostragem dos índices Espectrais e da Temperatura de Superfície Terrestre no Município de Goiânia}

A amostragem dos índices espectrais e da temperatura de superfície terrestre para as diferentes coberturas e padrões de urbanização no município de Goiânia, foi realizada de forma aleatória. Para cada ponto gerado aleatoriamente foi construída uma malha de $3 \times 3$ pixels, que visa cobrir uma área de amostragem com maior representatividade.

Como as imagens de índices espectrais e a termal possuem resolução espacial distintas, respectivamente 30 e 60 metros, foi necessário criar 2 malhas (uma com distância entre pontos de 30 e outra com $60 \mathrm{~m}$ ), que cobriram áreas com cerca de $8.100 \mathrm{~m}^{2}$ para as imagens de índices espectrais, e $32.400 \mathrm{~m}^{2}$ para termal ETM+ 6 .

O procedimento para criação da malha $3 \times 3$ em editor de planilha é ilustrado na figura 3. Na figura 4 é apresentado um exemplo da malha $3 \times 3$ utilizada na amostragem dos índices espectrais.

\begin{tabular}{|cc|ccc|cc|}
582622,755 & 8271289,033 & 582652,755 & 8271289,033 & 582682,755 & 8271289,033 \\
582622,755 & 8271319,033 & 582652,755 & 8271319,033 & 582682,755 & 8271319,033 \\
582622,755 & 8271349,033 & 582652,755 & 8271349,033 & 582682,755 & 8271349,033
\end{tabular}

Coordenadas centrais (dados de entrada)
Coordenadas geradas direita
Coordenadas geradas esquerda
Cordenadas geradas acima e abaixo

Figura 3: Procedimento para geração de malha $3 \times 3 \mathrm{em}$ editor de planilhas. Inicialmente coleta-se a coordenada do ponto gerado aleatoriamente, esta coordenada é inserida no centro da malha (cor de preenchimento laranja), automaticamente são gerados os outros oito pontos (cor de preenchimento verde e azul) por meio de determinações matemática em cada célula. 


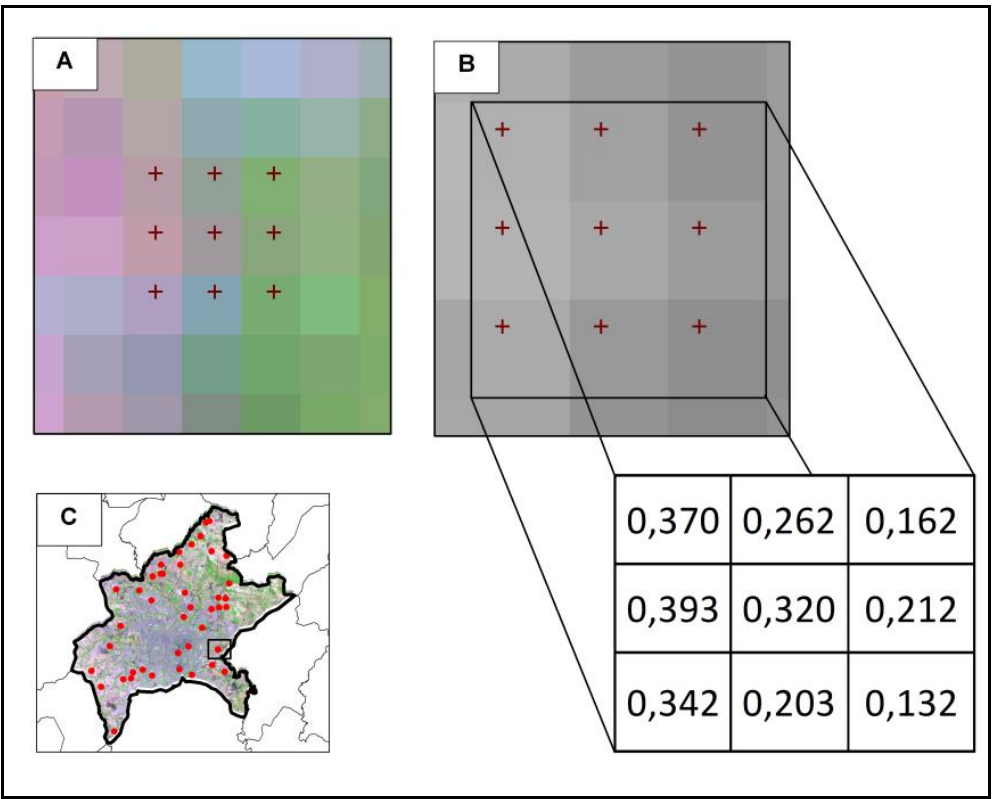

Figura 4 - Malha 3x3 utilizada para amostragem. Imagem Landsat ETM+15/08/2002. A Composição colorida (RGB 543), com pontos de amostragem. B - Imagem NDBI, com pontos de amostragem e seus respectivos valores. $C$ - Localização dos pontos amostrados, com destaque para o ponto representado nas figuras $\mathrm{A}$ e $\mathrm{B}$ (envolvido por um quadrado).

Para cada ponto, foi gerada uma média dos valores amostrados nos noves pixels, tanto para temperatura quanto para os índices NDBI e SAVI. Os valores de média foram processados em softwares estatísticos, nos quais foram gerados tabelas e gráficos para análise e reflexão sobre a relação entre o uso e cobertura da terra e a temperatura de superfície terrestre.

Com base na imagem de alta resolução (Quickbird 2002) e nos dados do MUBDG v.22, cada ponto foi detalhado com precisão quanto a cobertura da terra, a densidade de urbanização e arborização, bem como, em que bairro cada ponto se localiza. Cada um dos 36 pontos foi catalogado e foram distribuídos em 11 distintas classes, sendo elas: áreas verticais, alta densidade horizontal, média densidade horizontal, baixa densidade horizontal, chácaras de lazer, condomínio horizontal de alto padrão, agricultura, pastagem seca, corpos hídricos e coberturas vegetais. Na figura 5 é ilustrado exemplos de chaves de interpretação utilizadas nas distinções entre o tipo de uso e cobertura dos 36 pontos. 


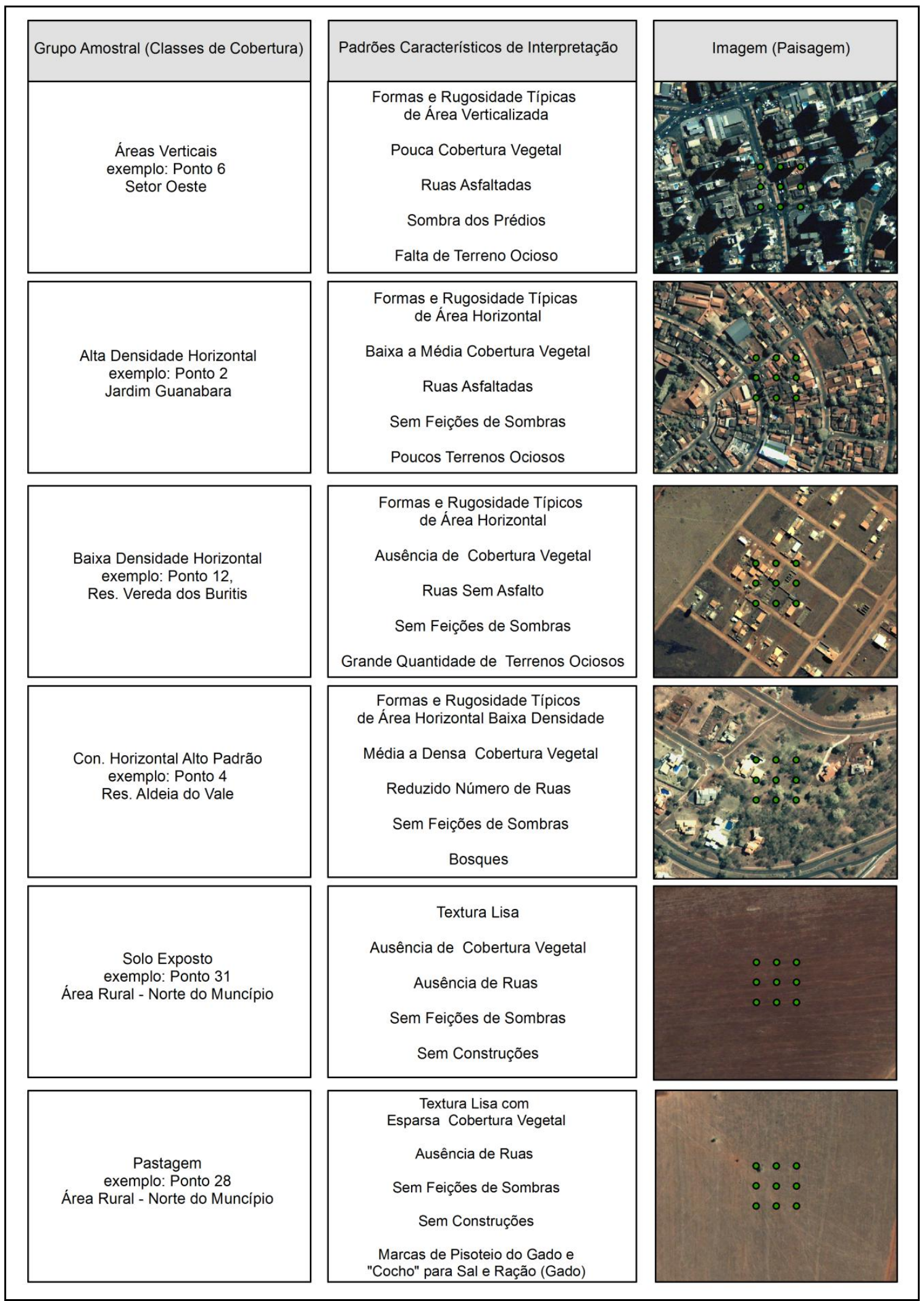

Figura 5: Exemplos de chaves de interpretação utilizadas para o catálogo dos pontos amostrados em distintas classes de cobertura e uso da terra. 


\section{RESULTADOS E DISCUSSÕES}

\section{Análise da Temperatura de Superfície Terrestre para 15/08/2002}

A análise visual da carta de temperatura de superfície terrestre para o dia 15 de agosto de 2002 (Figura 6) indica a predominância das faixas de temperatura superficiais mais altas $\left(>34^{\circ} \mathrm{C}\right.$ ), apenas uma pequena porção do território municipal apresenta faixas amenas de temperatura (entre 23 e $30^{\circ} \mathrm{C}$ ). Por meio do uso da imagem Quickbird e através de composições coloridas obtidas a partir das bandas ópticas Landsat, foi possível observar que, em geral, áreas de vegetação densa a média, apresentam temperaturas entre 23 ${ }^{\circ} \mathrm{C}$ e $30 \stackrel{\circ}{\circ}$, enquanto para a área urbana, foram registrados valores entre $34{ }^{\circ} \mathrm{C}$ e $36 \stackrel{\circ}{\circ}$.

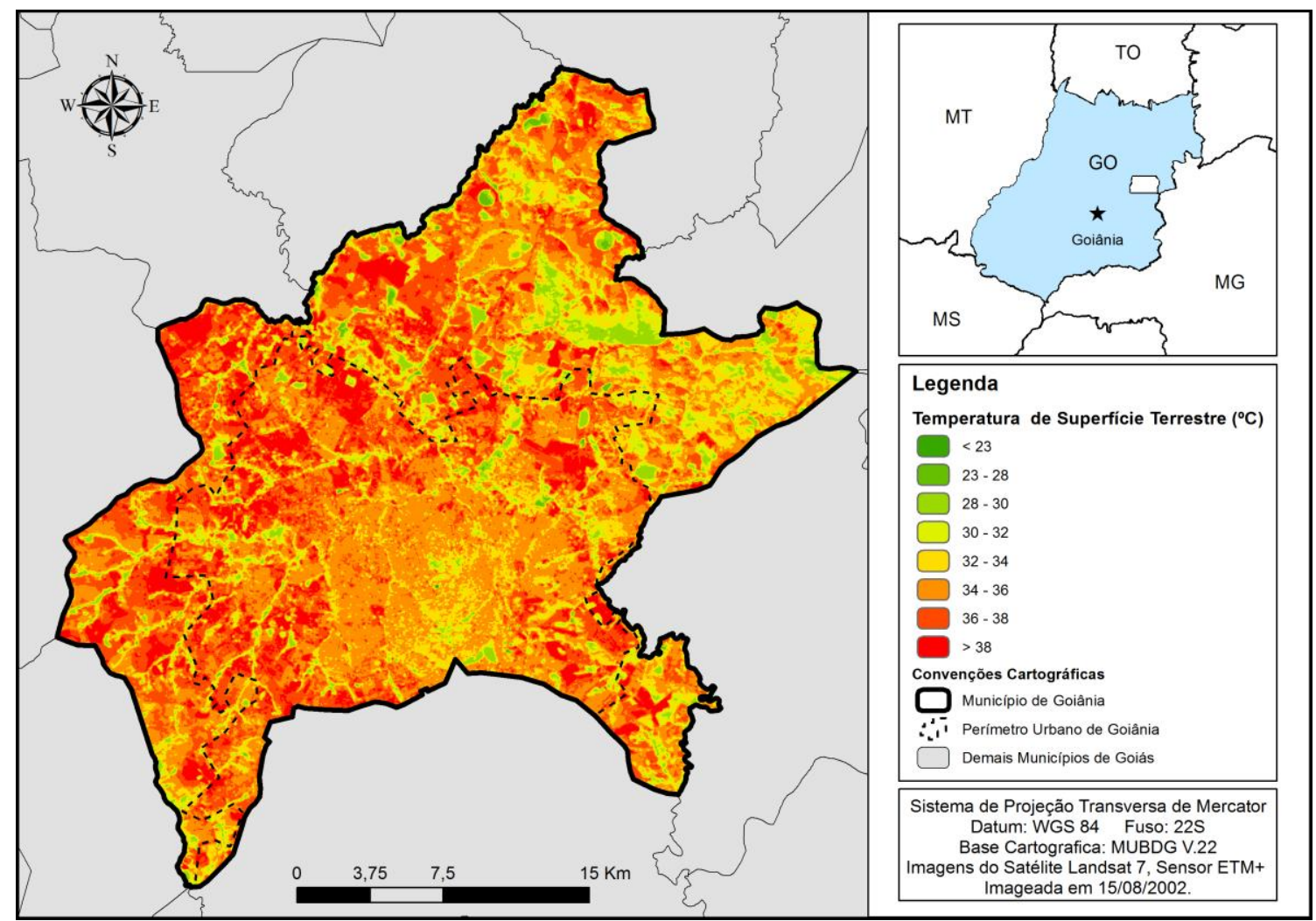

Figura 6: Carta de temperatura de superfície terrestre do município de Goiânia/GO, obtida a partir de imagens Landsat 7 ETM+ (15/08/2002). 
$\mathrm{Na}$ análise focando a malha urbana, bairros periféricos que em 2002 eram dotados de ruas sem asfalto e pouca ou nenhuma cobertura vegetal, registraram temperaturas superficiais mais altas em relação aos bairros afastados do centro e com infra-estrutura (asfalto) consolidada. Áreas verticais apresentaram temperaturas mais amenas, na faixa de 32 e $34 \stackrel{\circ}{\circ} \mathrm{C}$. Em fato, áreas com alto nível de verticalização, prédios próximos, ao lançarem sombras uns sobre os outros, tendem a criar nichos de temperaturas amenas (PRIMAVESI et. al., 2007).

Quanto às feições intra-urbanas detectáveis, é possível localizar e descriminar parques e áreas verdes, as quais apresentam temperaturas mais amenas, como visto no Parque Areião e Parque Vaca Brava (Figura 7), Jardim Zoológico, Bosque dos Buritis e, até mesmo o gramado do Estádio Serra Dourada. Outras feições intra-urbanas que apresentaram temperaturas amenas foram os telhados constituídos por metais, geralmente cobrindo galpões e construções em áreas industriais da cidade. Esta característica peculiar, também observada em superfícies vítreas, se deve a baixa correlação positiva entre a temperatura cinética e a quantidade de fluxo radiado (JENSEN, 2009), bem como a diminuição da emissividade, quanto maior a rugosidade da superfície (NOVO, 2008, p. 43).

Matas de galeria (principalmente do Rio Meia Ponte e do Ribeirão João Leite), pivôs centrais, o Jardim Botânico e o Parque Estadual Altamiro de Moura Pacheco, passíveis de serem discriminados nas imagens, apresentaram temperaturas amenas (entre $<23$ e $30^{\circ} \mathrm{C}$ ) comparativamente às outras feições da paisagem. As áreas de pastagens cultivadas registraram um comportamento termal variado, com temperaturas variando de 32 a $36{ }^{\circ} \mathrm{C}$, semelhante às registradas em áreas urbanas. Este comportamento se deve ao fato de que, no mês de agosto, as pastagens secas, comparativamente aos corpos mais úmidos, apresentam maiores amplitudes térmicas, ao mesmo tempo em que a menor evapotranspiração aumenta o fluxo de calor sensível (PRIMAVESI et. al., 2007, p. 23). 
$\mathrm{Na}$ figura 7 é possível vislumbrar um panorama do comportamento termal superficial de paisagens intra-urbanas em Goiânia.

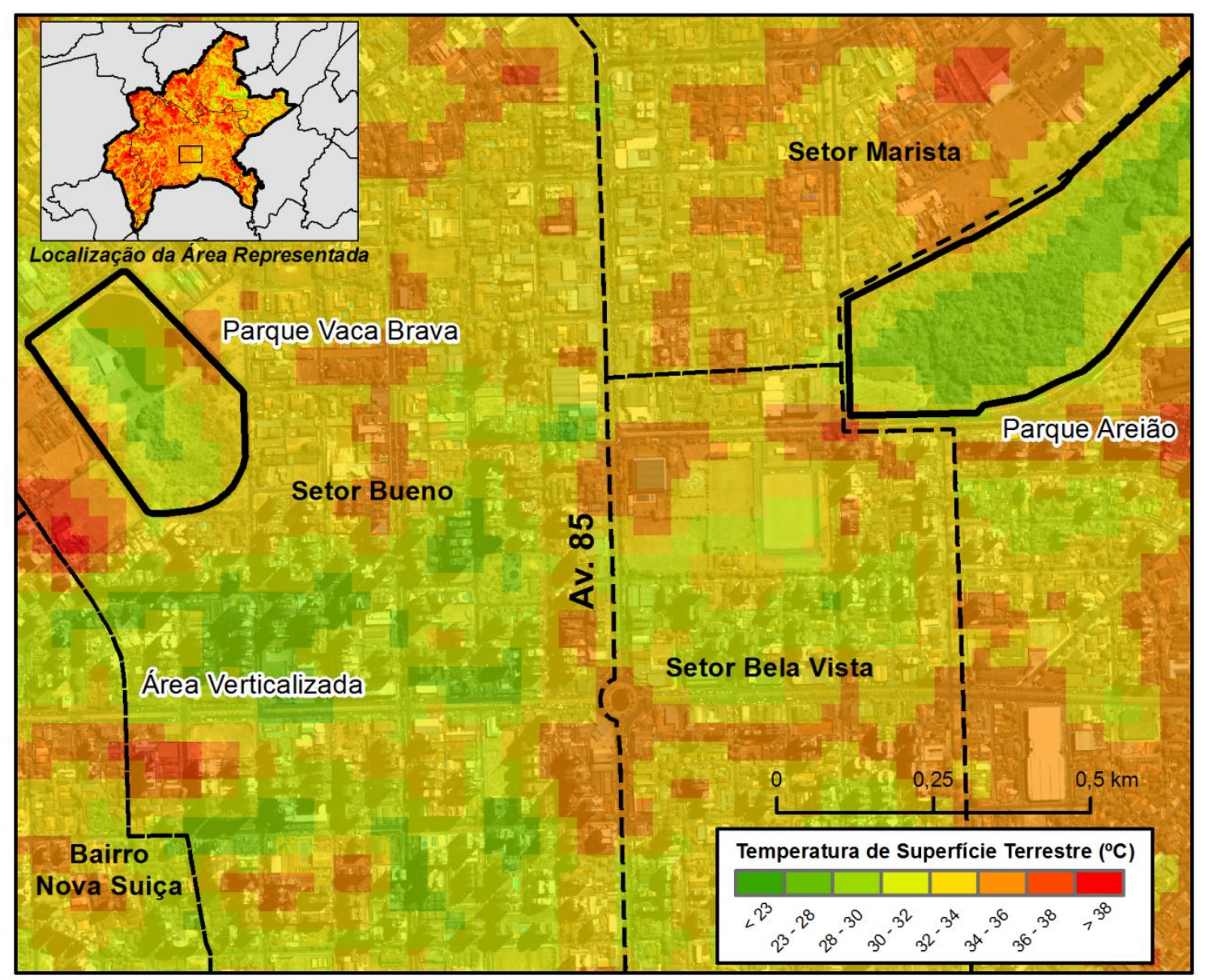

Figura 7: Comportamento termal superficial de paisagens intra-urbanas em Goiânia (15/08/2002). Parques e áreas verticalizadas com temperaturas amenas em relação às demais áreas urbanizadas.

\section{Índices Espectrais, Temperatura de Superfície Terrestre e Cobertura da}

\section{Terra}

O NDBI influência positivamente a temperatura de superfície terrestre (figura 8), no modelo $74 \%$ ( $r^{2}$ de 0,74 ) da variação da temperatura de superfície terrestre foi explicado pela variação do NDBI. Portanto, NDBI e temperatura são variáveis com correlação significativa, isto é, em geral um alvo que possui alto valor de NDBI, tende a possuir valores elevados de temperatura superficial. Dessa maneira, um modelo que considere NDBI e Temperatura possui uma boa precisão explicativa. 
O SAVI apresentou uma influência negativa em relação à temperatura de superfície terrestre (figura 9) e, apenas $27 \%$ de sua variação responde pela variação dos valores de temperatura de superfície terrestre. Nesse contexto de correlação pouco significativa, os resultados indicam que a temperatura superficial dos 36 pontos amostrados estão variando em função de outras variáveis, não sendo, portanto, o SAVI uma boa variável explicativa.

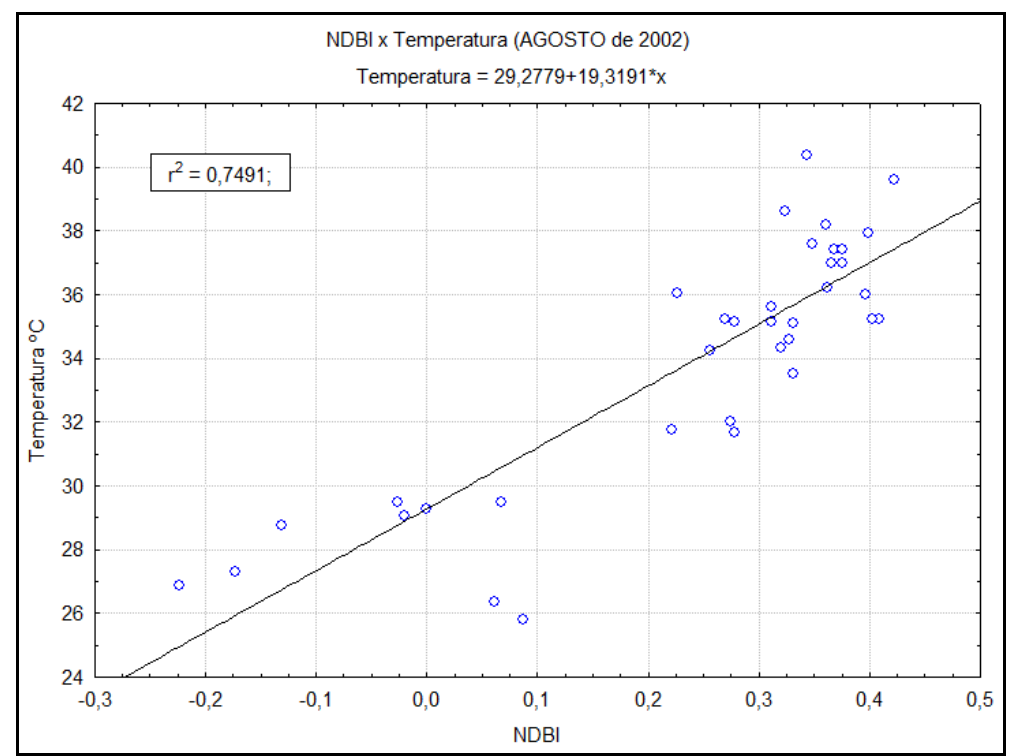

Figura 8: Gráfico de dispersão NDBI x Temperatura de Superfície Terrestre ETM+6.

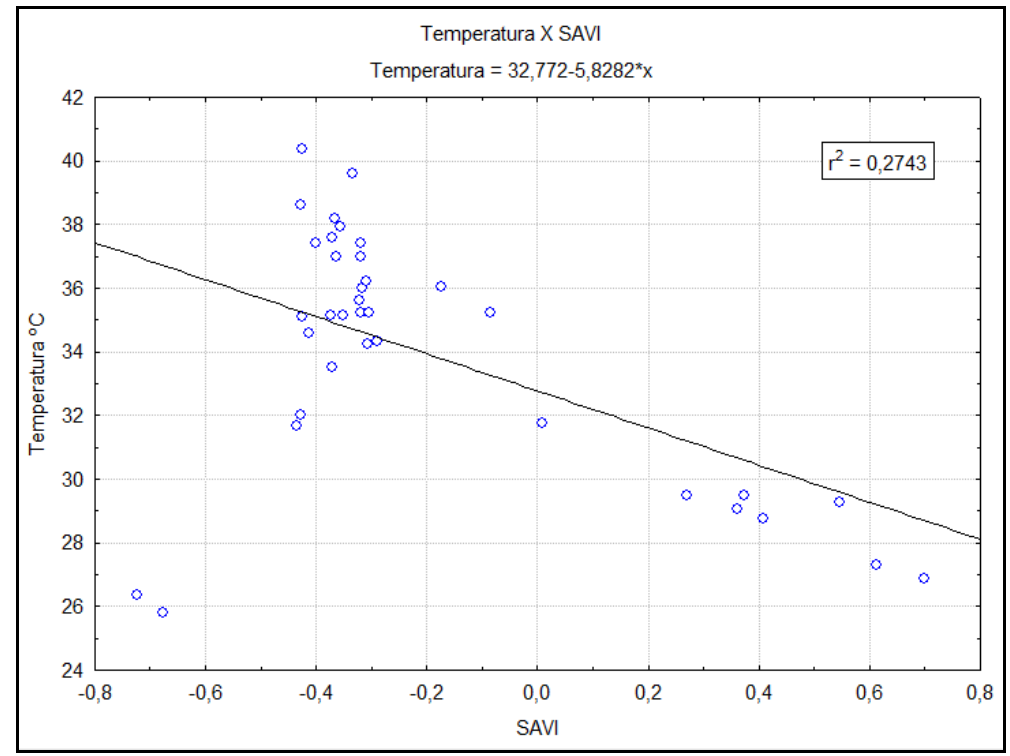

Figura 9: Gráfico de Dispersão SAVI x Temperatura de Superfície Terrestre ETM+6. 
Os dois lances de tabela a seguir (tabela 2) apresentam os dados médios de temperatura de superfície terrestre, SAVI e NDBI, bem como as observações feitas por meio de análise dos dados de referência para cada um dos 36 pontos amostrados.

Tabelas 2 - Dados médios de TST, SAVI e NDBI dos pontos amostrados e suas respectivas classes.

\begin{tabular}{|c|c|c|c|c|c|}
\hline \multicolumn{6}{|c|}{1 - Áreas verticais } \\
\hline Ponto & Bairro & TST & $\mathrm{NDBI}$ & SAVI & Obs. \\
\hline 5 & Setor Central & 34,61 & 0,33 & $-0,41$ & \multirow{3}{*}{$\begin{array}{l}\text { Verticalização de alta densidade, } \\
\text { Pouca cobertura vegetal, ruas } \\
\text { asfaltadas, sombra dos prédios }\end{array}$} \\
\hline 6 & Setor Oeste & 31,66 & 0,28 & $-0,43$ & \\
\hline 8 & Alto do Setor Bueno & 32,01 & 0,27 & $-0,43$ & \\
\hline \multicolumn{6}{|c|}{2 - Alta densidade horizontal } \\
\hline Ponto & Bairro & TST & NDBI & SAVI & Obs. \\
\hline 1 & Jd. Pompeia & 35,16 & 0,31 & $-0,37$ & \multirow{3}{*}{$\begin{array}{c}\text { Ruas com asfalto, baixa cobertura de } \\
\text { árvores }\end{array}$} \\
\hline 2 & Jd. Guanabara & 35,62 & 0,31 & $-0,32$ & \\
\hline 13 & Conj. Vera Cruz & 34,33 & 0,32 & $-0,29$ & \\
\hline 33 & Bairro Floresta & 37,58 & 0,35 & $-0,37$ & Ruas sem asfalto \\
\hline 34 & Conj. Hab. Madre Germana & 33,53 & 0,33 & $-0,37$ & Ruas sem asfalto \\
\hline \multicolumn{6}{|c|}{3 - Média densidade horizontal } \\
\hline Ponto & Bairro & TST & NDBI & SAVI & Obs. \\
\hline 3 & Vale do sonhos & 37,01 & 0,37 & $-0,36$ & $\begin{array}{c}\text { Sem asfalto, nenhuma cobertura } \\
\text { vegetal }\end{array}$ \\
\hline 15 & Res. Recanto do Bosque & 40,38 & 0,34 & $-0,43$ & $\begin{array}{c}\text { Sem asfalto, nenhuma cobertura } \\
\text { vegetal }\end{array}$ \\
\hline \multicolumn{6}{|c|}{4 - Baixa densidade horizontal } \\
\hline Ponto & Bairro & TST & NDBI & SAVI & Obs. \\
\hline 12 & Res. Vereda dos Buritis & 37,40 & 0,38 & $-0,40$ & Ruas sem asfalto \\
\hline \multicolumn{6}{|c|}{5 - Chácaras de lazer } \\
\hline Ponto & Bairro & TST & NDBI & SAVI & Obs. \\
\hline 29 & St. Mansões do Campus & 36,07 & 0,23 & $-0,17$ & $\begin{array}{c}\text { Média cobertura vegetal, ruas sem } \\
\text { asfalto }\end{array}$ \\
\hline \multicolumn{6}{|c|}{6 - Condomínio horizontal de alto padrão } \\
\hline Ponto & Bairro & TST & NDBI & SAVI & Obs. \\
\hline 4 & Aldeia do Vale & 35,22 & 0,27 & $-0,08$ & $\begin{array}{l}\text { Pequena densidade horizontal, média } \\
\text { cobertura vegetal, reduzido número } \\
\text { de ruas, ruas asfaltadas, bosque e } \\
\text { grama. }\end{array}$ \\
\hline 9 & Granville & 35,16 & 0,28 & $-0,35$ & \multirow{2}{*}{$\begin{array}{l}\text { Média densidade horizontal, } \\
\text { gramíneas e ruas asfaltadas }\end{array}$} \\
\hline 10 & Jardim Florença & 34,24 & 0,26 & $-0,31$ & \\
\hline
\end{tabular}


Continuação da Tabela 2 - dados médios de TST, SAVI e NDBI dos pontos amostrados e suas respectivas classes.

\begin{tabular}{|c|c|c|c|c|c|}
\hline \multicolumn{6}{|c|}{7 - Solo exposto/Loteamento em implantação/Feições antrópicas variadas } \\
\hline Ponto & Bairro/Local & TST & NDBI & SAVI & Obs. \\
\hline 7 & $\begin{array}{l}\text { Alphaville Flamboyant - } \\
\text { Implantação }\end{array}$ & 37,43 & 0,37 & $-0,32$ & $\begin{array}{l}\text { Solo Exposto, Gramíneas, traçado de ruas } \\
\text { asfaltado }\end{array}$ \\
\hline 11 & $\begin{array}{l}\text { Moinho dos Ventos - } \\
\text { Implantação }\end{array}$ & 38,18 & 0,36 & $-0,37$ & Gramíneas, Ruas sem asfalto \\
\hline 14 & Aterro Sanitário & 38,63 & 0,32 & $-0,43$ & Solo Exposto \\
\hline 20 & Autódromo & 37,94 & 0,40 & $-0,36$ & Gramíneas, Pista com Asfalto \\
\hline 31 & Área Rural - Norte Município & 39,61 & 0,42 & $-0,33$ & Solo Exposto - Preparação Agricultura \\
\hline 36 & ETE - Implantação & 35,09 & 0,33 & $-0,42$ & Solo Exposto \\
\hline \multicolumn{6}{|c|}{ 8-Agricultura } \\
\hline Ponto & Região & TST & NDBI & SAVI & Obs. \\
\hline 21 & Área Rural - NE & 29,26 & 0,00 & 0,55 & Pivô Central - Ativo \\
\hline 23 & Área Rural - N & 26,88 & $-0,22$ & 0,70 & Pivô Central - Ativo \\
\hline 25 & Área Rural - Extremo Norte & 27,30 & $-0,17$ & 0,61 & Pivô Central - Ativo \\
\hline 26 & Área Rural & 28,78 & $-0,13$ & 0,41 & Pivô Central - Ativo \\
\hline \multicolumn{6}{|c|}{9 - Pastagem seca } \\
\hline Ponto & Região & TST & $\mathrm{NDBI}$ & SAVI & Obs. \\
\hline 22 & Área Rural - NE & 35,25 & 0,41 & $-0,32$ & Sem cobertura vegetal \\
\hline 28 & Área Rural - N & 36,01 & 0,40 & $-0,32$ & Sem cobertura vegetal \\
\hline 30 & Área Rural - N & 36,98 & 0,38 & $-0,32$ & baixa cobertura vegetal \\
\hline 32 & Área Rural - N & 35,22 & 0,40 & $-0,30$ & $\begin{array}{c}\text { Baixa cobertura vegetal, próxima a corpos } \\
\text { hídricos }\end{array}$ \\
\hline 35 & Área Rural - SW & 36,22 & 0,36 & $-0,31$ & baixa cobertura vegetal \\
\hline \multicolumn{6}{|c|}{10 - Corpos hídricos } \\
\hline Ponto & Bairro/Região & TST & NDBI & SAVI & Obs. \\
\hline 17 & Aldeia do Vale & 25,80 & 0,09 & $-0,68$ & Lago de Finalidade Paisagística \\
\hline 27 & Área Rural - N & 26,36 & 0,06 & $-0,72$ & Circundada por Pastagem \\
\hline \multicolumn{6}{|c|}{11 - Coberturas vegetais } \\
\hline Ponto & Bairro/Local & TST & NDBI & SAVI & Obs. \\
\hline 16 & $\begin{array}{l}\text { Parque Altamiro de Moura } \\
\text { Pacheco }\end{array}$ & 29,48 & 0,07 & 0,27 & $\begin{array}{l}\text { Vegetação Densa, Além dos limites da Malha } \\
\text { Urbana }\end{array}$ \\
\hline 18 & Aldeia do Vale & 29,48 & $-0,03$ & 0,37 & Bosque, Circundado por malha urbana \\
\hline 19 & Jardim Botânico & 29,07 & $-0,02$ & 0,36 & $\begin{array}{c}\text { Vegetação Densa Circundada por malha } \\
\text { urbana }\end{array}$ \\
\hline 24 & Área Rural - Extremo Norte & 31,76 & $-0,04$ & 0,33 & Vegetação Densidade Média \\
\hline
\end{tabular}


Observa-se que todas as variáveis amostradas, temperatura superficial (graus Celsius), NDBI e SAVI apresentaram os menores valores em relação às amostras colhidas sobre os corpos hídricos (pontos 17 e 27), para as quais temos como valores médios $26,08-0,07$ e $-0,70$ respectivamente para temperatura, NDBI e SAVI. Portanto, o NDBI e o SAVI funcionam como bons parâmetros na distinção desse tipo de alvo em relação aos tipos de cobertura vegetação e área urbana.

Os pontos amostrados com cobertura de vegetação e agricultura (pivôs) apresentam valores semelhantes para as variáveis temperatura e NDBI, cabese ressaltar que os pivôs estavam ativos e, portanto detentores de vegetação sadia, com alto teor de umidade decorrente da irrigação. As amostras de agricultura são dentre todas as que apresentam maiores valores de SAVI, em média 0,31 maior que as áreas de vegetação, e o NDBI apresenta valores próximo a zero ou negativos para estes conjuntos de amostras. Quanto aos pontos amostrados com cobertura vegetais circundados por cobertura urbana, curiosamente, apresentam valores maiores de SAVI que os pontos amostrados em área rural, como exemplo podemos tomar o ponto 16, o Parque Estadual Altamiro de Moura Pacheco, de vegetação densa e fora dos limites da malha urbana, e o ponto 18, Bosque do Residencial Aldeia do Vale, com valores SAVI de 0,27 e 0,37 respectivamente.

As amostras com cobertura de pastagens apresentam altas temperaturas e altos valores de NDBI, por conseguinte, apresentam baixos valores de SAVI. Os valores de temperatura superficial recuperados pelas pastagem apresentam o valor médio de 35,94ํㅡ, portanto, semelhante com os valores de temperatura recuperados para os pontos nas diversas classes de área urbana. As pastagens também apresentaram os maiores valores de NDBI, a única distinção é que o SAVI apresentou valores maiores em relação à área urbana, porém também negativo.

Em análise dos seis grupos de amostras em área urbana, o grupo que apresentou menores temperaturas foi o composto pelas amostras em áreas verticalizadas (em média 32,61 ํㅡ). Áreas de alta densidade horizontal 
possuem temperaturas mais amenas quando possuem ruas asfaltadas, bairros sem cobertura asfáltica recuperaram maior temperatura de superfície. O NDBI se encontra semelhante em todas as classes urbanas, com ressalva para os condomínios horizontais de alto padrão e a amostra para chácaras de lazer os quais registraram menores valores. Os maiores valores de NDBI recuperados para as amostras de cobertura urbana, dizem respeito à baixa e média densidade horizonal, talvez por influência da grande área de solo exposto neste tipo de cobertura. Assim, quando temos áreas com solo exposto o NDBI não se faz um bom parâmetro para efetuar a distinção entre áreas verticais e alta densidade de ocupação.

Em resumo, O SAVI não é eficiente na distinção entre áreas pivôs e vegetação, pois áreas de agricultura irrigada registraram valores mais elevados de SAVI em detrimento de áreas vegetadas. Pastagens e solo exposto apresentam altos valores de NDBI e altas temperaturas, semelhantes às registradas em amostras de áreas urbanas. As amostras de área urbana não foram responsáveis nem pelos maiores valores de temperatura, nem pelos mais elevados valores de NDBI, sendo os solos expostos detentores de tais valores. Para melhor observar estas relações, a tabela 3 apresenta as médias dos valores para os três parâmetros em relação os diferentes grupos de amostras.

Tabela 3: Valores médios das variáveis analisadas para os diferentes grupos amostrais.

\begin{tabular}{cccc}
\hline Grupo Amostral & TST $\left.{ }^{\circ} \mathrm{C}\right)$ & NDBI & SAVI \\
\hline Áreas verticais & 32,76 & 0,29 & $-0,42$ \\
Alta densidade horizontal & 35,24 & 0,32 & $-0,34$ \\
Média densidade horizontal & 38,69 & 0,35 & $-0,39$ \\
Baixa densidade horizontal & 36,07 & 0,23 & $-0,17$ \\
Chácaras de lazer & 37,40 & 0,38 & $-0,40$ \\
Condomínio horizontal de alto padrão & 34,87 & 0,27 & $-0,25$ \\
Solo exposto/Feições antrópicas variadas & 37,81 & 0,37 & $-0,37$ \\
Agricultura & 28,06 & $-0,13$ & 0,57 \\
Pastagem seca & 35,94 & 0,39 & $-0,31$ \\
Corpos hídricos & 26,08 & 0,07 & $-0,70$ \\
Coberturas vegetais & 29,95 & 0,00 & 0,33 \\
\hline
\end{tabular}




\section{CONSIDERAÇÕES FINAIS}

O presente trabalho apresentou uma aproximação inicial do uso de dados de sensoriamento remoto para determinação da temperatura superficial em ambiente urbano. Os procedimentos estatísticos efetuados se mostraram suficientes para construir um raciocínio e modelar o comportamento das variáveis analisadas. Entretanto, os resultados das análises visuais e estatísticas indicam certa complexidade quanto às respostas termais dos diferentes alvos que compõem a paisagem, seja em função da forma e da organização espacial, ou em função de seus constituintes físico-minerais e comportamento no tocante da interação destes com a energia eletromagnética.

As temperaturas superficiais registradas para o dia 15 de agosto de 2002 indicaram maiores valores no limiar do perímetro urbano, não sendo as áreas de urbanização densa e verticalizadas detentoras das maiores temperaturas. Locais com cobertura de solo exposto, como áreas de plantio, queimadas e bairros sem cobertura asfáltica chamaram a atenção por responderem pelas maiores temperaturas registradas (maiores que $38^{\circ} \mathrm{C}$ ). As temperaturas amenas registradas $\left(<23\right.$ e $\left.30^{\circ} \mathrm{C}\right)$ correspondem a áreas de vegetação densa, como as matas de galerias, o Jardim Botânico e o Parque Estadual Altamiro de Moura Pacheco, registrando-se uma diferença de até $8^{\circ} \mathrm{C}$ em relação a áreas antropizadas e áreas vegetadas.

Em razão de terem sido utilizadas imagens do mês de agosto, as temperaturas registradas para as pastagens também se apresentaram elevadas, substancialmente maiores que as registradas em áreas urbanas. $O$ fato causa estranhamento, porém como se constituem praticamente de biomassa seca no mês de agosto, as pastagens não desempenham efeito vaporizador e não agem como regulador térmico, em vista dos baixos ou inexistentes valores de evapotranspiração.

Quanto aos índices espectrais, o NDBI apresentou uma correção significativa em relação aos valores de temperatura $\left(r^{2}=0,74\right)$. Entretanto, o SAVI não apresenta uma boa correlação, com $r^{2}$ de 0,27 . Os valores de NDBI 
para área urbana e rural foram semelhantes, o que não ocorreu em relação ao SAVI que retornou valores significativamente distintos para os dois tipos de uso e cobertura da terra. Os pivôs centrais retornaram maiores valores de SAVI do que áreas com cobertura vegetal densa e pastagens. Áreas com solo exposto apresentam valores NDBI semelhantes à de áreas urbanizadas. Portanto, 0 índice não apresentou aproveitamento efetivo na distinção dos alvos urbanos em relação aos demais alvos.

Neste sentido, conclui-se que as imagens utilizadas, imageadas no mês de agosto (estação seca no bioma Cerrado) não se mostraram adequadas para recuperação dos valores de $\mathrm{NDBI}$, pois mesmo em áreas rurais o índice retornou altos valores. Em fato, espera-se melhor desempenho do NDBI para imagens colhidas no período úmido. Quanto ao SAVI, não se observa este empecilho, pois as áreas de cobertura vegetal foram bem realçadas. Para o estudo das distinções entre temperaturas urbanas e rurais, as imagens também não se configuraram melhor opção, em razão das áreas de pastagens dotadas de pouco ou nenhuma umidade apresentarem temperaturas maiores ou até superiores que as registradas em área urbana.

As conclusões reforçam a ideia de importância dos parques ambientais e da arborização urbana, não só como paisagismo, ou seja, como um mero elemento arquitetônico, mas como um elemento de manutenção do conforto térmico no espaço urbano, modificando o microclima, trazendo diversos benefícios para a população na medida em que contribui na qualidade de vida e saúde.

Não obstante, destaca-se também a importância das árvores na criação de microclimas em áreas rurais, as quais predominantemente compostas por pastagens no município de Goiânia apresentaram altos valores de temperatura superficial, constatação esta que pode indicar maior arborização em área urbana em relação a área rural, a qual conta com aproximadamente 950 mil árvores em vias públicas, em torno de 0,79 unidade por habitante (AMMA, 2008). Tal arborização, no entanto, não considera as diferenças socioeconômicas da população e nem os diversos padrões de urbanização 
promovidos pela hierarquização social, ou seja, pela desigualdade. A qualidade de manutenção não é igual para todas as áreas verdes da cidade, curiosamente mais bem preservadas e mantidas em áreas de práticas de especulação imobiliária e bairros de classes mais bem favorecidas.

\section{AGRADECIMENTOS}

Este trabalho se insere entre as várias iniciativas do Laboratório de Processamento de Imagens e Geoprocessamento do Instituto de Estudos Sócio-Ambientais da Universidade Federal de Goiás (LAPIG / IESA / UFG www.lapig.iesa.ufg.br) voltada ao monitoramento sistemático e gestão territorial do bioma Cerrado. O primeiro autor é bolsista de mestrado do Conselho Nacional de Desenvolvimento Científico e Tecnológico (CNPq), enquanto o segundo autor é bolsista de Produtividade em Pesquisa (1C) do Conselho Nacional de Desenvolvimento Científico e Tecnológico (CNPq).

\section{REFERÊNCIAS BIBLIOGRÁFICAS}

AMMA - Agência Municipal Do Meio Ambiente - Goiânia. Relatório do Plano

Diretor de Arborização Urbana de Goiânia, 2008. Disponível online em: $<$ http://www.goiania.go.gov.br/download/amma/relatorio Plano Diretor.pdf>, acesso em 24 de out. 2012.

COMDATA - Cia. de processamento de dados do município de Goiânia. MUBDG - Mapa Urbano Básico Digital de Goiânia. CD-ROM Profissional Versão 22 - Parte integrante do SIGGO V22. Prefeitura de Goiânia. 2010.

CHANDER, G., B. MARKHAM., D. HELDER. Summary of current radiometric calibration coefficients for Landsat MSS, TM, ETM+, and EO-1 ALI sensors. Remote Sensing of the Environment, Vol. 113, p. 893-903, 2009.

CHAUL, N. F. A construção de Goiânia e a transferência da capital. Goiânia: Cegraf-UFG 1988.

GEORGE, P. A geografia ativa. São Paulo: Difel, 1968. 
HANQIU, XU. Extraction of Urban Built-up Land Features from Landsat Imagery Using a Thematic Oriented Index Combination Technique. Photogrammetric Engineering \& Remote Sensing, 1381-1391, 2007.

JENSEN, J. R. Sensoriamento Remoto do Ambiente: uma perspectiva em recursos terrestres. 2da Edição traduzida pelo Instituto Nacional de Pesquisas Espaciais - INPE. São Paulo, Parêntese, 2009. 672 p.

LANDSBERG, H. E.. O Clima das cidades. Tradução: Prof. Dr. Tarik Rezende de Azevedo, DG, FFLCH, USP. Revisão Profa. Dra. Maria Elisa Siqueira Silva, DG, FFLCH, USP. Revista do Departamento de Geografia, 2006 n. 18, p. 95111.

NASCIMENTO, M. A.; PODESTÁ Filho, A. Carta de risco de Goiânia. Boletim Goiano de Geografia. Goiânia, v.13, n.1, p. 95 - 105, 1993.

NOVO, E. M. L. M. Sensoriamento Remoto: Principios e Aplicações. São Paulo: Blucher, 2008.

PRIMAVESI, O.; ARZABE, C.; PEDREIRA, M. S. Mudanças climáticas: visão tropical integrada tropical. São Carlos, SP: Embrapa Pecuária Sudeste, 2007.

SANTOS, Milton. Por uma economia política da cidade. São Paulo: Hucitec/Educ, 1994.

WENG, Q. Thermal infrared remote sensing for urban climate and environmental studies: Methods, applications, and trends. ISPRS Journal of Photogrammetry \& Remote Sensing, 64: 335 - 344, 2009.

ZHA, Y.; GAO, J.; NI, S. Use of normalized difference built-up index in automatically mapping urban areas from tm imagery. International Journal of Remote Sensing, v. 24, n. 3, p. 583-594, 2003.

Recebido em 06/03/2012.

Aceito em 07/09/2012. 